\title{
Víctor Iturralde Rúa y la especificidad de lo infantil. Un primerísimo primer acercamiento
}

\section{Eseverri, Máximo}

Resumen:

La trayectoria de Víctor Iturralde (1927-2004) es hoy reconocida en Argentina en campos tan diversos como los estudios de cine, el cineclubismo, la animación experimental, la investigación en comunicación, la literatura infantil o la gestión cultural orientada a los niños. Su trabajo constituye un eslabón fundamental en el desarrollo y la transmisión de tradiciones artísticas, culturales e intelectuales en general ubicadas en los márgenes de (o en oposición a) las instituciones tradicionales y los medios masivos.

Palabras clave: Víctor Aitor Iturralde Rúa - Cine infantil - Cineclubismo Animación - Crítica cinematográfica

\section{Cuadernos del Centro de Estudios de Diseño y Comunicación N74}

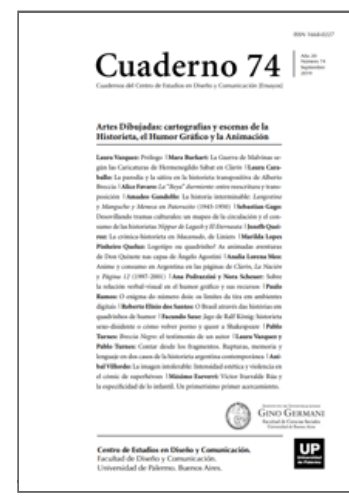

ISSN: 1668-0227

Artes Dibujadas:

cartografías y

escenas de la

Historieta, el Humor

Gráfico y la

Animación

Año XX, Septiembre 2019, Buenos

Aires, Argentina | 256 páginas

descargar PDF

ver índice de la publicación

Ver todos los libros de la publicación

compartir en Facebook

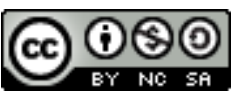

Esta obra está bajo una Licencia Creative Commons Atribución-NoComercialCompartirlgual 4.0 Internacional

\section{${ }^{*}$ ) Licenciado en Ciencias de la}

Comunicación (Facultad de Ciencias Sociales - Universidad de Buenos Aires) y Magíster en Sociología de la Cultura y Análisis Cultural (Instituto de Altos Estudios Sociales / Universidad Nacional de San Martín). Es profesor de Historia de los Medios en la carrera de Comunicación Social (FCS-UBA) y Secretario Académico de la Maestría en Periodismo en la misma casa de estudios. Dirige la colección Cosmos - temas de cine para la Editorial Universitaria de Buenos Aires (Eudeba) y realiza tareas de investigación y edición en la Escuela de Maestros (Ministerio de Educación del Gobierno de la Ciudad Autónoma de Buenos Aires) y el Ministerio de Educación y Deporte de la Nación. El autor agradece a Ana Broitman y Adrián Muoyo, quienes garantizaron el acceso a la hemerografía que se utilizó en este artículo, y a Fernando Martín Peña, Gustavo Bombini, Alberto Ferro y Raúl Manrupe, por su generosa orientación y sus comentarios.

Cuando muchacho empecé a estudiar Química en la Facultad. Lo hice porque me resultaba simpático trabajar con materiales, hacerlos cambiar de color, de estado. Quizás pudiera hallar una sustancia desconocida hasta el momento: jser un descubridor! 
Tenía un profesor fascinante, mezcla de sabio con prestidigitador: era un viejito dedicado, que hacía experimentos a la vista de sus alumnos, ¡Y le salían bien! ¡Qué placer estar en sus clases! Nosotros en un aula grande, él al frente, moviendo matraces, probetas, calentando líquidos, agitando soluciones rojas y azules, introduciendo papelitos en los frascos para lograr que lo que era amarillo se convirtiera en violeta, o saliera humo violento, y se produjera una ligera explosión. Él sonreía pícaramente detrás de sus anteojos mientras explicaba, mientras daba las claves de sus sortilegios, y nosotros escribíamos en los cuadernos sin perdernos uno solo de sus hechizos.

Pero para llegar a la Química había un largo trecho, poblado de números, electricidad, barómetros complicados, estudios sobre vibraciones.

La meta estaba lejos.

Un día conocí el cine.

Otra vez la magia, pero ahora envolviéndome, haciéndome parte de ella. Imágenes, mundos maravillosos, proyectores, sombras, el triquitrí de los mecanismos, el olor de la película vieja. Hasta que aprendí a hacer dibujos animados. Ahora el mago era yo. Fue entonces cuando pensé: ¿para qué estudio? A mí no me interesaba descubrir verdades. Pero en esos momentos no había muchas instituciones en las cuales se pudiera investigar. Me quedaba la posibilidad de trabajar con un microscopio (como lo había hecho mi madre, que me regaló uno de juguete). Pero para esto no necesitaba pasarme años en la Facultad. O bien podría poner un laboratorio y fabricar drogas (en casa muchas veces había ahuyentado a mi familia con las emanaciones o gases tóxicos de mis experimentos). Peor, para esto necesitaba dinero, capital. ¿Y si tenía dinero, no podía usarlo en otra cosa? Dejé la carrera, seguí enamorado del cine. Desde entonces hago cine, escribo un poco, o doy clases. O viajo por otros países y conozco gente linda. Y oigo hablar en ruso, francés, alemán, finlandés, vietnamita, inglés, italiano. O escucho hablar con el agradable cantito que emplean los colombianos, los bolivianos. Y me encuentro con muchos argentinos de Salta, Trelew, Misiones, Córdoba, Tucumán.

Observé que en mi país el cine que consumen los niños podría ser mucho mejor. Pero ¿acaso existe un cine mejor?

Sí. Sí que existe. Yo lo vi. Es un cine bello, abundante, original. Por eso me ocupé de conseguir estas películas mejores, para luego difundirlas, proyectarlas a los chicos. Y fundé cine clubes infantiles en los cuales podría exhibir estas cintas, rodeado por muchos pibes, y podría verlas de nuevo, y hablar sobre ellas, y jugar, y pintar, evocarlas con placer. Y llevé esta iniciativa a la televisión, donde mostré películas, hablé con los chicos sin pedirles "un fuerte aplauso" para este muñeco o para este televisor, y les expliqué cómo es la magia de la televisión, cómo se realizan algunos trucos de cine (como el profesor viejito).

Así comienza a presentarse Víctor Aitor Iturralde Rúa (VAIR) en las páginas finales de su novela El bramido horripilante1 (1987). Cada línea de esta peculiar autobiografía encierra muchos años de experiencias en los mundos de la cinefilia, el cineclubismo, el periodismo, la publicidad, la investigación de cine, la divulgación, la realización cinematográfica y televisiva y, sobre todo, el trabajo con y para niños. 
A poco más de diez años de su muerte, por desgracia, el tamaño de la obra de VAIR sólo se compara con la enorme dificultad para acceder a ella: sus libros se encuentran agotados y sus realizaciones audiovisuales se han perdido o son prácticamente inhallables. Tampoco se encuentran disponibles sus producciones televisivas, ni han sido reunidas las colaboraciones periodísticas y críticas que publicó en múltiples medios gráficos, ni existe, más allá de sus propios libros, un racconto de las diferentes experiencias de enseñanza, divulgación y cineclubismo para niños y adultos que Iturralde desarrolló durante medio siglo.

VAIR es hoy reconocido en Argentina como una figura destacada y hasta fundante en campos tan diversos como la moderna crítica cinematográfica, los estudios de cine, el cineclubismo, la animación experimental, la investigación en comunicación, la literatura infantil o la gestión cultural orientada a los niños. Su trabajo constituye un eslabón fundamental en el desarrollo y la transmisión de tradiciones artísticas, culturales e intelectuales que en general se han ubicado en los márgenes de (y en ocasiones en oposición a) un canon propio de las instituciones tradicionales y los medios masivos de comunicación. Repartidos (y tensionados) entre el ejercicio profesional de la escritura o la realización audiovisual comercial y un trabajo vocacional como divulgadores, artistas o emprendedores culturales; numerosos actores del campo de la cultura local como VAIR dieron forma a trayectorias singulares, caracterizadas por lo autodidáctico, lo autogestivo, lo erudito, lo comunitario y la celebración de lo creativo, lo diverso y lo alternativo, frente a una cultura hegemónica que consideraban masificada y alienante2 .

El impacto de su incansable trabajo es hoy innegable y puede comprobarse en el testimonio de los numerosos hombres y mujeres del arte y la cultura que lo reconocen como pionero y maestro. En un homenaje realizado en 2011 en el Museo de Arte Latinoamericano de Buenos Aires3 , Fernando Martín Peña definió a VAIR como "realizador, animador, documentalista, docente, escritor, crítico, erudito, investigador, historiador, cineclubista, anarquista y bohemio". Ya en 1962 un artículo sobre él declaraba que "su labor es vastí- sima", y desde ese momento siguió creciendo de manera sostenida a lo largo de décadas, en las que publicó varios volúmenes, tradujo otros, dictó conferencias, cursos y talleres a lo largo de todo el país y el exterior, fue jurado en diferentes certámenes nacionales e internacionales, participó en los dos cineclubes más importantes de la Argentina, realizó documentales y cortometrajes animados con diversas técnicas, logró construir lentamente un archivo fílmico de obras para niños y adultos, montó cineclubes infantiles y muestras itinerantes, practicó el periodismo en medios masivos y especializados y llevó adelante diferentes ciclos televisivos. En 1981 recibió el Diploma al Mérito de la Fundación Konex. Seguiría trabajando luego al menos por dos décadas más.

Víctor Iturralde nació en el barrio de Flores de la ciudad de Buenos Aires el 6 de agosto de 1927. En su juventud estudió Química en la Facultad de Ciencias Exactas de la Universidad de Buenos Aires, donde fue compañero del Premio Nobel César Milstein, pero pronto abandonó sus estudios para abocarse al cine, en el que se formó de manera autodidáctica a través de la lectura de libros y revistas de cine, y de charlas y seminarios dictados por referentes de la talla de Leopoldo Torre Nilsson, Pablo Tabernero o Isidro Maiztegui. A mediados de los cincuentas ya había logrado concretar varios cortos de animación y algunos trabajos de cine publicitario.

Por esa época tradujo libros del inglés para las editoriales Acme, Eudeba y Muchnick. Participó en el cineclub Gente de Cine y en la revista homónima que editaba ese espacio, junto a Carlos Burone, Rolando Fustiñana, Salvador Sammaritano, Nicolás Mancera o Edmundo Eichelbaum, entre otros4 . Allí, VAIR halló, por fin, un espacio para la investigación y el análisis cinematográficos. 
Participó del Films Museum de Peña Rodríguez, fue cofundador de la Cinemateca Argentina y del Cineclub Núcleo, y fue una de las plumas de la revista Tiempo de Cine. También escribió crítica en las revistas especializadas Butaca Crítica (allí realizó su primera reseña, sobre En cualquier lugar de Europa Hungría,1947- de Geza von Radvanyi), Tiempo de América, Cine ensayo y Karina, y en diarios de Argentina y el extranjero.

Fue docente de Historia del Cine y asesor cinematográfico del Departamento de Extensión en la Universidad de Buenos Aires. En 1958 dirigió, para esa universidad, un documental de veinticinco minutos llamado Crónica en Maciel, sobre una experiencia de educación popular realizada en esa isla. La película aborda, entre otros temas, las condiciones laborales de los obreros portuarios y brinda a las mujeres de la zona información sobre distintos momentos del embarazo. Ese mismo año integró las Misiones Pedagógicas organizadas por la Dirección Nacional de Cultura. En los ochentas y noventas retomó la enseñanza universitaria como titular de cátedra en la materia Historia Universal del Cine en la carrera de Artes de la Facultad de Filosofía y Letras y de Historia del Cine Argentino y Latinoamericano en la (por entonces nueva) carrera de Imagen y Sonido de la Facultad de Arquitectura, Diseño y Urbanismo, en ambos casos en la Universidad de Buenos Aires. Y dictó un seminario de animación en la Fundación Universidad del Cine, a poco de que ésta fuera fundada.

También ejerció la docencia en la Universidad Nacional de Córdoba en las materias Introducción al Cine y Cine de Animación y dictó cursos en el Instituto Torcuato Di Tella y el Instituto Summa. En este último desarrolló clases de perfeccionamiento docente para maestros de educación inicial y nivel primario. A mediados de los ochentas volvería a trabajar en formación docente continua con educadores del sistema público porteño a través de una serie de propuestas desarrolladas en la Escuela de Capacitación, refundada luego del retorno de la democracia. Allí realizó paralelamente proyecciones para niños en diferentes escuelas de la ciudad de Buenos Aires5 . También participó en propuestas de formación para cortometrajistas. Enumerar las diferentes charlas, seminarios, talleres, cursos y conferencias que dictó es una tarea interminable6 .

Entre las películas que más quería y acostumbraba a proyectar se encontraban El globo rojo de Lamorisse, El Golem de Paul Wegener, Nosferatu de Murnau, o Codicia de Erich Von Stroheim, y también las obras de Dreyer, Eisenstein o Flaherty. Fue un difusor del neorrealismo italiano, el nuevo cine indio, la animación checa o los films de Georges Méliès y Norman McLaren, entre muchas otras cinematografías. Estableciendo contactos con los servicios culturales de distintas embajadas, logró acceder a muchas obras por fuera del circuito comercial y fue su promotor y difusor, llegando incluso a restaurar artesanalmente las copias para poder exhibirlas.

En 1956, con su amigo Floreal Seijas, creó el Recreo Infantil La Calesita, inspirado en parte por las experiencias de la educadora y cineasta parisina Sonika Bo7 y la "Escuela Viva" de las maestras rosarinas Olga y Leticia Cossettini. Allí los niños del barrio de Flores participaban de charlas y talleres de arte. Pronto comenzaron a realizarse también proyecciones de películas. A esta experiencia siguió la apertura de diferentes cineclubes infantiles en barrios residenciales de la ciudad de Buenos Aires y asentamientos del conurbano, como El duendecito, que tuvo, entre otras sedes, las Galerías Pacífico y la Alianza Francesa de Buenos Aires, o diferentes locales en San Isidro, Provincia de Buenos Aires. Sus exhibiciones lograron en poco tiempo atraer a cientos de niños que, en muchos casos, nunca habían concurrido a una sala de cine. Luego siguieron otras experiencias cineclubísticas para infantes, que concretó en colaboración con otros entusiastas que buscaban seguir su ejemplo y método de trabajo: La casita, Pla Pla, Platero, Mamarracho (en la ciudad de La Plata), Miranda y Mirón, Casimira (ambos en la zona de Quilmes), Muni Muni y El Principito, esta última en la Biblioteca 
“Mariano Moreno" de Bernal8 . También, en 1982, montó experiencias similares para grupos de niños discapacitados. VAIR llegó desarrollar una red nacional de cineclubes infantiles, a los que abastecía con las películas de su propia filmoteca, que alcanzó unos mil títulos. Fue becario del Fondo Nacional de las Artes y la Embajada de Canadá para estudiar técnicas especiales de animación en ese país. Allí se familiarizó con el funcionamiento de la pantalla de alfileres desarrollada por Alexandre Alexeieff y Claire Parker. A su regreso, montaría en la Facultad de Arquitectura de la UBA un dispositivo similar para demostrar su funcionamiento. En los noventas aún continuaba organizando y animando proyecciones en el barrio de Belgrano, en el sótano de un bar cerca de su domicilio, en la Feria de Mataderos y, en marzo de 1996, en la Manzana de las Luces los días viernes, donde revivió por última vez su cineclub infantil.

En 1964, como encargado de publicidad y marketing de la distribuidora de cine "Rank", para el lanzamiento del film Mary Poppins, organizó un desfile con una caravana de autos, a través de un convenio con la automotriz Citroën. También trabajó en la Secretaría de Turismo de la Nación, en el edificio Olivetti, donde se ocupó del microcine y la filmoteca de esa cartera. Se desempeñó como jurado en una Muestra de Cine de Arquitectura (1969), en los certámenes de la Unión de Cineastas de Paso Reducido (UNCIPAR), el Festival de Cine de Moscú (1984) y en los festivales internacionales de cine para niños de Saint-Maló y Río de Janeiro. A mediados de los setentas realizó junto a Mario Grasso el espectáculo "Vamos al biógrafo", en el que ambos, vestidos de época, presentaban placas de linterna mágica y películas como las de Charles Chaplin, mientras el Arquitecto Eduardo Cerbera musicalizaba en vivo tocando un piano. El espectáculo se realizó en Buenos Aires y en Villa Gessell.

En 1979, en plena dictadura militar, fue uno de los que impulsó y sostuvo el Cineclub Jaen, en la biblioteca anarquista "José Ingenieros", que se convirtió, junto con el Cineclub Núcleo, en uno de los más longevos de Buenos Aires. En los ochentas, animó proyecciones para niños los sábados a las 17 en salas A-B y Enrique Muiño del Centro Cultural General San Martín9 .

En televisión, comenzó a trabajar junto a Mario Grasso en un canal de la ciudad de Córdoba. A principios de los setentas acompañó a la conductora Canela en el programa La luna de Canela, por Canal 7. Iturralde realizaba un bloque del programa, titulado "El cineclub de la luna". Allí recibió como invitado, entre otros, al documentalista Jorge Prelorán. Más tarde, en el verano de 1976 creó y condujo el programa Cine Club Infantil, también junto a Mario Grasso. El programa se emitió los domingos por la mañana en Canal 13 de Buenos Aires hasta junio de 1979. Fue retransmitido por trece repetidoras del interior del país y más tarde pudo verse en un canal de Video Cable Comunicación (VCC), pocos meses después de inaugurada ese servicio de TV10. El programa se sostuvo cerca de cuatro años en el aire. En 1984, también en Canal 13, realizó el programa Taller del sol, en el que diferentes profesionales presentaban a los niños una misma temática, y también el programa de proyección de películas Filmoteca. En 1984, luego de un viaje por Europa, regresó con el objetivo de reeditar el festival internacional de cine infantil gestado en los sesentas por Cándido Moneo Sanz y crear un festival argentino de animación. Tenía esos proyectos entre manos al menos desde 1980. Pero tuvo que rearmar su agenda, porque fue convocado como asesor fílmico en Argentina Televisora Color (canal 7, la TV pública). A fines de los ochentas realizó en para esa misma señal el programa de verano La ventana y participó con un bloque en otro de Hugo Midón11. En los noventas fue uno de los asesores del multipremiado ciclo Caloi en su tinta.

Además de su trabajo como exhibidor, divulgador y crítico, Iturralde realizó también cortos de animación. Entre los trabajos de Iturralde que se conservan se encuentran Ideí- tas (1952), Hic...! (1953), Puna (1954), Piripipí 
(1956), Baladita (1956), Petrolita (1958, realizado en Cinemascope y restaurado por la Filmoteca Buenos Aires) También realizó Las manos del Marqués (1964), un comercial de caramelos marca Sugus para la empresa Suchard (1957) y otro corto publicitario para la agencia de prensa estatal Télam en 1970, pata audiovisual de la campaña "Para Télam el amor también es noticia"12. Estos trabajos experimentales fueron realizados con diversas técnicas de trabajo directo sobre el celuloide, similares a las que utilizó el escocés Norman Mc Laren para la National Film Board de Canadá. Contra lo que se supone, señala el investigador Fernando Martín Peña, los primeros de estos films fueron hechos antes de que Iturralde conociera la obra de McLaren13. Y VAIR también fue un autor. Su obra más recordada consiste en una serie de novelas para niños para la colección Coquena - Libros del quirquincho: El onésimo soñó un cuete (1987), El bramido horripilante (1987)14, Las cabezas sin hombres (1991) y Los dinosaurios de la seis de la tarde (1994); más otras dos para la editorial Métodos: Los emplastos de Don Zafiro (1988) y El invasor de los sueños (1991). Sin embargo, ya a inicios de los sesentas había comenzado a trabajar como autor de libros para niños: Yo pregunto a la jirafa (Buenos Aires: Norte, 1962). Y hasta entrados los noventas siguió colaborando en diferentes obras para público infantil como Re-divertido con letras $6^{\circ}$ y $7^{\circ}$ grado (en coautoría, Buenos Aires: La colmena, 1993). Sumado a su trabajo literario, Iturralde publicó libros de cine como AH Biografía de Alfred Hitchcock (1960) como parte de una serie de fascículos editados por el Cineclub Núcleo. O El ojo oye, el oído ve. Vida, obra y técnica de Norman McLaren: un genio del cine (1981), editado por la Embajada de Canadá en Buenos Aires. Iturralde concretó, además, dos libros específicos sobre los consumos culturales de los niños argentinos y el cineclubismo infantil local. Fueron editados con veinte años de diferencia. En 1964, la Editorial Universitaria de Buenos Aires (Eudeba) publica Qué ven, qué leen nuestros hijos. Es la primera vez que VAIR sistematiza sus reflexiones y su experiencia en forma de libro. Todo comienza con una serie de imágenes, las primeras que Iturralde recuerda en el inicio de su experiencia cinematográfica, que lo llevan, en su adultez, a interesarse por "la relación imagen-niño" y la forma en la que ésta moldea la experiencia infantil. En la breve introducción del libro, VAIR avisa a los lectores: "no soy educador, sino un curioso que quiere a los niños y trata de respetarlos". La advertencia es, a un mismo tiempo, una excusa por la ausencia de referencias al campo de la pedagogía y la declaración de una posible ventaja frente a los educadores profesionales porque "explicará por qué pude aproximarme a los niños desde otro punto de vista, sin despertar desconfianzas, obteniendo testimonios espontáneos y verosímiles". En Qué ven, qué leen nuestros hijos Iturralde manifiesta una relación de amor-odio con la institución escolar: por un lado, expresa fascinación por aquellos espacios (como los laboratorios de química) en los que la escuela permite a los niños el ejercicio de la creatividad y la imaginación y, por el otro, demuestra desazón por "la ciega burocracia que considera al niño como un futuro contribuyente". El anarquismo que VAIR militó en su juventud, se encuentra aquí con la mirada sesentista sobre la educación formal como instancia represiva y la apuesta por una formación y una crianza libre de esas ataduras.

El libro, sin embargo, no se ocupa de la escuela, sino de otras instituciones, las audiovisuales, que por esta época ganan cada vez mayor terreno en la experiencia infantil. Frente a las instituciones educativas, que dialogan con la familia desde hace tiempo y establecen espacios claramente delimitados; la TV, el cine o las historietas (cada una de estas instancias posee un capítulo entero, más otro final de integración) tienden a relacionarse directamente con el niño, sin la mediación adulta, en un vínculo caracterizado por el consumo, la publicidad comercial y el entretenimiento. Mientras la TV -que Iturralde describe como un "Gólem" en el living del hogar- y las revistas de historietas ingresan directamente en el espacio doméstico, el cine continúa poseyendo un espacio propio (si bien la TV comienza lentamente a alterar esta vicisitud). Sin embargo, en la oscuridad de la sala, el niño también se encuentra finalmente solo frente a la pantalla. 
Iturralde está interesado por los usos que los niños hacen de la historieta, el cine y la TV, cómo operan las tradiciones escolares en la construcción de los vínculos con objetos culturales, qué tipo de personajes tiene para ofrecer la historieta mexicana en relación con la argentina, qué obras son originales y cuáles fruto de la traducción y la adaptación; cómo se dirimen las franjas etarias del público infanto-juvenil, las estéticas que se ponen en juego, las calidades del papel de las historietas, las características de la impresión, el diseño de las páginas, la configuración del mercado local. Por ese camino, Iturralde se detiene en casos, cuenta anécdotas, describe personajes y los compara, enumera géneros, repasa los clásicos y describe los nuevos relatos. Presta atención a cómo se aborda en diferentes casos el ejercicio de la violencia. Caen bajo su lupa los personajes de Disney, Quinterno u Oesterheld. Estamos en 1964, y los niños porteños aún poseen un espacio de encuentro en las veredas, las plazas y los últimos terrenos baldíos. El circo compite con el cine, el teatro y, de manera cada vez más desigual, con la TV. Iturralde está preocupado por los primeros sondeos de opinión y ratings que, señala, no se condicen con las entrevistas que ha realizado a diferentes niños. Le preocupan los jingles publicitarios mezclándose con las canciones tradicionales, o los héroes televisivos que usan "calibre 44". Boris Karloff, Superman o Lassie se encuentran ahora "entre las paralelas del hábito" de los niños. La TV es parte insoslayable de su cotidianeidad, sin que la escuela ni ninguna otra institución del estado o la sociedad civil la haya pensado críticamente ni en profundidad: los docentes, señala, parecieran no tener nada que enseñar a sus alumnos sobre este nuevo objeto que gravita en sus vidas. El libro constituye un llamamiento a diferentes instituciones a reconocer la situación, sensibilizarse con ella y actuar al respecto. Dos décadas después, sin embargo, reconocerá que se trata de una tarea ciclópea, que quienes se ocupan de la infancia sólo han logrado dar forma a expresiones de deseo y urgencia sin mayores consecuencias, y que es posible y necesario "rodear" el problema a través de una herramienta al alcance de cualquiera: los cineclubes infantiles.

En Cine para los niños, VAIR inicia su disquisición con una suerte de declaración de principios, bajo el título "Por qué este libro":

Hace muchos años que me preocupo por los niños en relación con el cine. Pero advierto que en la Argentina ellos no tienen opciones para ver un cine específico. Tampoco la televisión llena esta falta. Aunque abundan las declaraciones, los congresos referidos a la televisión y el niño, las frases ampulosas, los funcionarios que muestran el ceño y proclaman huecas convicciones con voz engolada haciendo referencias al futuro, la cultura, nuestros valores, y una cantidad de sustantivos imponentes y adjetivos no siempre apropiados, pero retumbantes.

Los cines comerciales "usan" a los niños, aprovechan su natural ingenuidad para convertirlos en consumidores.

La desorientación monta a las mesas de los cronistas de cine, y ellos tampoco manifiestan su opinión en este tema cuya urgencia me parece día tras día más acuciante: en mi país los niños no tienen un cine que les convenga.

La distorsión es enorme; el tiempo se pierde irremediablemente; la agresión a la sensibilidad e inteligencia de los niños, de mis propios hijos, es implacable; el vértigo geométrico con que se confunde todo el panorama no parece hallar impedimentos.

Es un momento grave. 
Y lo más doloroso es la ceguera, el taparse los oídos para no querer escuchar, porque esto ocurre en Argentina y otros países más, pero no en todo el mundo. Hay naciones donde el fenómeno del cine y los niños ha sido encarado con madurez, serenidad, franqueza.

¿Por qué no aquí? (1984, p. 9)

Este volumen editado en 1984 por Corregidor representa un último esfuerzo de VAIR por exponer de manera detallada una posición política en torno a formas de abordaje a la infancia desde el estado y la sociedad civil, que contengan al mercado y posibiliten a los niños y sus familias prácticas y consumos culturales alternativos. A diferencia de lo que había ocurrido veinte años antes, en este caso todo el libro se centra en lo cinematográfico, que es descripto en detalle como hecho técnico, fenómeno cultural, negocio o herramienta de trabajo de y para los más pequeños. Cine para los niños es, finalmente, la apuesta por plasmar una memoria del aporte realizado a lo largo de muchas décadas, tanto de VAIR como de otros promotores culturales, nacionales y extranjeros, que han trabajado junto a él o cuyo trabajo ha funcionado como ejemplo y fuente de su inspiración.

Página tras página, VAIR describe qué es el cine, cómo se hace, cómo funciona, cómo es el negocio, qué le sucede a un niño en una sala de cine a diferencia de un adulto, qué tipo de cines existen, qué tipo de películas, de dónde salen, cómo conseguirlas. El mismo procedimiento realiza con la TV -nuevamente identificada con el "Gólem" de la tradición hebrea-, la técnica y el negocio televisivo para, de inmediato, volver sobre cómo el cine se produce, distribuye y consume a través de la televisión. Todo es explicado con las palabras más sencillas, con opinión implacable, con la seguridad de aquél que siente conocer un fenómeno en profundidad, y el sordo resentimiento de quien advierte que no ha podido, pese al esfuerzo de toda una vida, alterar las reglas del juego.

Para entender el problema, afirma Iturralde, es necesario pensar quién enciende la TV y cuándo, cómo llegó el aparato a un hogar, dónde se ubica en el espacio doméstico, cómo se genera y emite la programación, cómo se organiza la labor cotidiana en un canal televisivo. Quienes trabajan en TV adquiriendo dibujos animados, afirma VAIR, no saben nada acerca de ellos. Todo el tono general es de durísima crítica, de desazón, con breves descansos como el siguiente "intermedio casi utópico":

La televisión correctamente empleada, con libretistas, sicólogos, plásticos idóneos, productores inteligentes, con gente que le confiera coherencia podría ser el medio más fascinante, útil, perfectible, eficiente, penetrante de todos los vehículos de la comunicación social.

Podría ser la más hermosa herramienta de la educación. (1984, p. 51)

Las críticas más duras de VAIR son para quienes practican la censura en el cine y la TV. Iturralde expone la burocracia ciega que gobierna todo el proceso, y cómo ésta es afectada por las reglas del mercado, el peso de la iglesia católica y, más en general, por un ciego y perimido encuadre moral. Todo es descripto con la forma de un relato que se vuelve humorístico. Es claro que el autor recurre a escenas que ha presenciado en su transcurrir por las salas de cine y los canales TV a lo largo de los años.

Toda la zona intermedia del libro está destinada a historizar diferentes experiencias de cineclubismo infantil, que Iturralde presenta como una forma de "rodear" los problemas que presentan la producción y el consumo de cine y TV para niños. Los cineclubes representan, tanto en los sesentas como en los ochentas, espacios situados, de 
base, reproducibles en una escala importante, en el marco de los cuales realizar una tarea de promoción cultural y educación con un alto grado de autonomía y alguna chance de acumulación política.

Tras recuperar algunas experiencias de "cine escolar" dirigido a niños en diferentes países en la Europa de entreguerras, VAIR se concentra en el trabajo de Sonika Bo, iniciado en 1933. Sus iniciativas comienzan a tener proyección internacional en 1945, luego de ser presentadas en un encuentro en la ciudad de Basilea, el primero consagrado al cine luego de la Segunda Guerra Mundial. Asistieron allí, entre otros, el fundador de la Cinemateca Francesa Henri Langlois, el historiador del cine Georges Sadoul, la investigadora Lotte Eisner o el realizador sueco Arne Suckdorf. La experiencia derivó en una red de proyecciones para niños en diferentes ciudades europeas y en la creación de una cinemateca especializada en cine infantil.

La otra experiencia fundadora recuperada por Iturralde es la de Arthur Rank en el Reino Unido. La iniciativa de realizar proyecciones regulares para niños se remonta a 1927, se detiene en 1939 a causa de la guerra y es recuperada en 1943, cuando comienzan a regresar a las grandes ciudades los niños que habían sido evacuados durante los bombardeos alemanes. La experiencia de estos clubes de cine para niños desbordan la promoción cultural, y encarnan un trabajo social de reconstrucción de los lazos comunitarios y del lugar de los niños en ese proceso. El trabajo de Rank influenció otras experiencias de cineclubismo infantil en Estados Unidos, Canadá o Australia. Si la obra de Sonika Bo había derivado en la creación de un archivo de películas, en Reino Unido, la labor de Rank llevará a la creación de instancias de realización cinematográfica, con un diseño de producción y lógicas de distribución y circulación pensadas en el contexto de una política cultural dirigida a los niños.

En la perspectiva de VAIR, lo esencial de estas experiencias es la puesta en foco de una especificidad del cine infantil, que va más allá de la realización y que implica formas originales de montar una proyección, programar las películas, o gestionar un espacio de expectación e intercambio entre los asistentes.

A estas dos experiencias europeas, Iturralde suma una argentina. Tras mencionar iniciativas estatales de cine escolar montadas por el Ministerio de Educación de la Nación15 o la Caja Nacional de Ahorro Postal durante los dos primeros gobiernos de Juan Domingo Perón, VAIR se concentra en una experiencia realizada entre 196016 y 1968: los festivales internacionales de cine infantil realizados por Cándido Moneo Sanz. El trabajo de este último complementa y enriquece la labor de Iturralde en Argentina17.

Finalmente, VAIR desarrolla en el libro su propia experiencia, que se inicia con el recreo infantil "La Calesita" a mediados de los cincuentas. Le sigue el cineclub "El Duendecito", fundado en 1967 en el barrio de Almagro. Iturralde funda nuevos espacios cineclubísticos en ciudades del interior como Río Cuarto, Santa Fe o Mercedes. Junto a un grupo de colaboradores crea una federación argentina de cineclubes infantiles, con filiales en Rosario, Avellaneda, Ramos Mejía, La Plata y varias más en la ciudad de Buenos Aires18. Iturralde presenta su trabajo televisivo junto a Mario Grasso como una instancia más de su labor cineclubística, es decir, como la televisación de una práctica situada, que de esa manera puede llegar a miles de niños, a partir del trabajo con un grupo estable de asistentes, de entre seis y doce años. En algunos programas muestran cómo se monta una pelea con mesas y botellas de utilería en un saloon del lejano oeste, o cómo se genera en cine una tormenta de arena, o cómo se logra que King Kong suba a una torre. En las últimas emisiones, VAIR logra emitir pequeños cortometrajes realizados por los mismos niños que asistían al programa, dos de los cuales eran sus propios hijos. 
El extenso cierre del libro corresponde a una descripción pormenorizada del funcionamiento de sus cineclubes: los aspectos técnicos, el perfil de los diferentes miembros del equipo, la obtención y uso de las películas, las actividades que pueden realizarse: el libro todo es una guía detallada de cómo crear y sostener un cineclub infantil.

Éste último es encarado como "lo contrario de un cine-debate, pues la estimulación es previa a la proyección". Una de sus premisas es el respeto por el espacio que el niño necesita: las salas tradicionales no se adaptan a los más pequeños, se encuentran "fuera de escala". Iturralde prefiere salones o casonas "que se ajustan a la realidad espacial de los niños", recintos que nunca se oscurecen por completo sino que permanecen iluminados o en penumbra, posibilitando en todo momento al niño verse, ver a los demás y reconocer su lugar. Los espectadores asisten munidos de un almohadón, que utilizarán para sentarse durante la proyección, u ocupan una colchoneta al llegar. Entre película y película, realizan ejercicios de relajación. Pueden pararse, moverse, ir al baño. Todos los niños se presentan y saludan, pueden participar del hecho fílmico como acomodadores o ayudando a proyectar, son interpelados en diferentes momentos y, luego de las proyecciones, participan de talleres y actividades relacionadas con las películas vistas. Iturralde promueve la formación de equipos interdisciplinarios para el armado de cineclubes infantiles: en todas sus iniciativas busca integrar psicólogos, docentes, artistas, especialistas en literatura. Propone estudiar las reacciones de los niños frente a las películas, recurriendo incluso a fotografías, y sistematizar esa información en un archivo junto con el resto de los datos de cada cinta. Un cineclub infantil, definió Iturralde19, "es un lugar donde un niño se deja fascinar por un filme, y donde la compañía de sus pares lo protege contra la angustia, la incertidumbre y la soledad".

VAIR falleció en Buenos Aires el 25 de enero de 2004 en un instituto geriátrico donde se había retirado poco tiempo antes. Su familia donó los filmes de su cinemateca personal a la Filmoteca Buenos Aires y el Instituto Nacional de Cine y Artes Audiovisuales, y una gran parte de su biblioteca a la Fundación Universidad del Cine.

\section{Para Fernando Martín Peña,}

Como buen librepensador, Iturralde privilegiaba aquellos films en los que la creación artística pura se demostraba tan posible como en la pintura o en la literatura, es decir, prescindente de las ataduras industriales y comerciales. Al mismo tiempo, enseñaba que el cine entendido de ese modo también era de realización accesible para cualquiera y apostaba al estímulo de la imaginación, la curiosidad, los valores humanistas, la comunicación. El arte y el conocimiento como caminos directos hacia una verdadera libertad individual20.

\section{Notas}

1. El mismo texto figura en todas las obras de VAIR publicadas en la colección "Libros del quirquincho".

2. Elina Adduci Spina (2015, p. 4 y ss) enfrenta a la figura de VAIR con la del empresario de TV Goar Mestre en el contexto de la década del sesenta, cuando el desarrollo de la TV comercial se cruza con una renovación en las concepciones de niñez (en 1959 la ONU había aprobado la Declaración de los Derechos del Niño) y la ampliación y diversificación de un mercado de lo infantil. Mientras Iturralde "trabajó por el desarrollo, el estímulo y la autonomía de los niños, Mestre, fundador de Canal 13 y su productora Proartel, trasmitió los valores de la sociedad burguesa a una infancia entendida como un nicho de mercado. Por su parte, el cine y la televisión 
fueron el medio y el campo de batalla de estos dos tipos de proyectos: el de la construcción del niño como sujeto u objeto del mercado".

3. La actividad se realizó como sección paralela del Tercer Festival Internacional de Cine para la Infancia y la Juventud, organizado por la Asociación Nueva Mirada y el Instituto Nacional de Cine y Artes Audiovisuales.

4. http://www.lanacion.com.ar/567209-victor-iturralde-un-apasionado-del-cine. Consultado 5/12/16.

5. La Escuela de Capacitación, Perfeccionamiento y Actualización Docente fue creada en 1984, sobre la base de un departamento de formación docente continua de la Secretaría de Educación de la entonces Municipalidad de la Ciudad de Buenos Aires, en funcionamiento desde 1978. Es una de las instituciones características de la apertura democrática en el ámbito educativo porteño, y funciona hasta hoy bajo el nombre "Escuela de Maestros". En sus inicios, la institución contaba con una sede central en una vieja casona del barrio de Belgrano (que fuera residencia de Lucio V. Mansilla) pero también realizaba actividades en diferentes escuelas de la ciudad. En sus cartillas de cursos pueden hallarse propuestas sobre historieta dictadas por Oscar Steimberg, u otras de canto coplero con caja a cargo de Leda Valladares. Desde el departamento de Arte y Comunicación coordinado en ese momento por Alberto Ferro, Iturralde y Roberto Sobrado organizaban, además de las propuestas para docentes, proyecciones en diferentes escuelas, en las que se utilizaban los recursos y la filmoteca desarrollados en los cineclubes y talleres de VAIR. La idea de integrar talleres para niños, proyecciones de películas y actividades de capacitación docente en el ámbito escolar reconoce un antecedente en la labor del Grupo C.IN.E (Cine Infantil Educativo), fundado en 1972. Iturralde realizó varias visitas a este grupo, cuyos miembros estaban interesados en la dinámica de trabajo que VAIR y sus colaboradores imprimían a sus cineclubes infantiles (entrevista personal realizada a Liliana Mazure, abril de 2014).

6. Entre muchas otras actividades: en los noventas, los sábados de enero de 1992 proyecta películas junto con su colaboradora Rosario Luna en el sexto piso del Centro Cultural General San Martín; en agosto de 1994 realiza un taller de cine para niños en El castillo del juguete, en el barrio de San Telmo de Buenos Aires, que incluye la proyección de un documental sobre plantas carnívoras (los asistentes tienen que llevar moscas y mosquitos), otro sobre música alemana y un espacio en el que los niños animan pintando sobre celuloide; en marzo de 1996 realiza su taller de cine infantil en la Escuela de Arte de Palermo, con la asistencia de Mónica Gruber.

7. Sonika Bo (su verdadero apellido era Kavounovsky) fundó el "Club Cinematográfico para niños Cendrillon" en París, Francia, en 1933. Veinte años después, la iniciativa contaba ya con una cinemateca con más de ochocientos films para niños. Iturralde también recupera la experiencia de los británicos Arthur Rank y Mary Field, quienes desarrollaron Children's Entertainment y Children's Film Foundation, con una orientación similar a la de Sonika Bo. Nótese que a mediados de los sesentas VAIR trabaja para una distribuidora llamada "Rank", que incluye en su catálogo películas para niños. Volveré sobre estas experiencias más adelante.

8. Romero y Sancho (2014: 245) refieren "Pla Pla" como "Bla Bla" y agregan a la lista una experiencia desarrollada en FUSEMIA, una institución para niños que también albergaba actividades del Collegium Musicum. 
9. En este espacio, en abril de 1988 Iturralde repite la experiencia de reenactment de las primeras funciones de cine gestada con Grasso, pero en solitario, nuevamente con la participación de Cerbera al piano y una joven que reparte golosinas entre el público. Pocos años después, a comienzos de los noventas, Iturralde trabajó en el proyecto de un largometraje llamado "Vientos de magia", que recurriría al lenguaje cinematográfico y la estética desarrollada por Georges Méliès. La película sería filmada con una cámara original de 1910, confeccionada por un socio del cineasta francés (revista La Maga, 10 de junio de 1992).

10. Iturralde también realizó tratativas para que el programa fuera emitido por el Canal 2 de La Plata, con auspicio del Ministerio de Educación de la Provincia de Buenos Aires (diario Convicción, 3 de febrero de 1983).

11. Hacia 1985 Iturralde trabajaba en un piloto televisivo llamado "El ojo del mago", que buscaba brindar un panorama de la historia del cine desde sus inicios hasta la actualidad (La Nación Revista, 2 de diciembre de 1984).

12. Raúl Manrupe (2004) refiere otros encargos de cortos publicitarios para las empresas Yacimientos Petrolíferos Fiscales (YPF), La Campagnola y Peugeot. Y otros cortometrajes experimentales: Duerme liebrecita (1956) y Botellita (1961).

13. En una entrevista publicada en el diario La Nación (11 de octubre de 1981) VAIR señala como referencia "una señora muy extraña", quien acerca al cineclub Gente de Cine un cortometraje llamado "Ideas". "Veíamos relieves, sombras -recuerda Iturralde-, pero nadie acertaba a saber, entre risas groseras e incontenibles, cómo estaba hecho". Más tarde, como parte de una apuesta, VAIR comienza a experimentar con una cámara Pathé Baby de 9,5 mm., rayando el celuloide y aplicándole, en base a sus conocimientos de química y a los consejos de un ex compañero universitario, solventes y colorantes. La entrevista refiere 1952 como el año en el que VAIR entra en contacto con la obra de McLaren. Iturralde lo conoció personalmente en 1954 durante la primera edición del Festival Internacional de Cine de Mar del Plata. Allí le obsequió una bolsa con quenas y una copia de una de sus películas (Manrupe, 2004: 42). Diez años más tarde, VAIR y Mc Laren volverían a encontrarse en Córdoba durante un festival internacional de animación. Al igual que Manrupe, Pablo Marín (2014) también ahonda sobre el carácter experimental de las películas realizadas por VAIR, y las coloca en diálogo con la obra del rosarino Luis Bras, o con la de artistas de vanguardia como Stan Brakhage.

14. En la reseña del libro, publicada en diario Clarín el 14 de enero de 1988, Carlos Silveyra rescata la "tensión dramática, aunque dándose algunos permisos para colocar sutiles toques de humor". Para Mónica Cerezales (2014, p. 2), la obra escrita de Iturralde, en especial Las cabezas sin hombres, recupera, a fines de los ochentas, elementos de lo siniestro para el canon de la literatura infantil argentina, junto con diferentes relatos de Ricardo Mariño y Ana María Shúa, entre otros.

15. Para una historia de las iniciativas estatales en torno al cine educativo ver Serra, 2011.

16. Otras experiencias locales en la primera mitad del siglo XX son los proyectos de cine escolar de la educadora Gerarda Scolamieri en la escuela "República de México" de la Ciudad de Buenos Aires, desarrolladas desde inicios de la década del 20 y hasta entrada la década del '40 (Scolamieri, 1946: 81-87), o tempranos cortometrajes gestados por fuera del mundo escolar como El pañuelo de Clarita (1919) y La niña del bosque (1917), ambos de Emilia Saleny (1894-1978) -considerada una de las primeras cineastas de América Latina-, El 
mono relojero (1933) de Quirino Cristiani -hoy reconocido como pionero mundial de la animación cinematográfica- o Upa en apuros (1941) de Dante Quinterno (Adduci Spina, 2015: 262).

17. Por el tamaño de su trayectoria, la figura de Moneo Sanz podría ocupar un artículo entero: el mismo Iturralde se sorprende de su capacidad de gestión al encargarse personalmente de prácticamente todos los aspectos de los festivales que organizaba. Estas son solo algunas de sus iniciativas: en 1943 crea la compañía teatral "Los títeres del triángulo" junto a Gregorio Verdi y José Vaccaro, tres años después inaugura un teatro sobre la calle Tucumán en la ciudad de Buenos Aires, que contiene una juguetería sin juguetes bélicos y un museo de muñecos, edita la revista Titirilandia, funda una asociación argentina de titiriteros, crea y dirige el estudio CADYA de cine documental y educativo, funda y dirige un grupo experimental de teatro, crea el Teatro Universitario de La Plata, desarrolla el primer curso de cinematografía de la Escuela Superior de Bellas Artes (Universidad Nacional de La Plata). En 1958 organiza el Primer Congreso Nacional de Medios Audiovisuales. Desarrolló una colección de muñecos de diferentes países, cuya donación constituyó la base del "Museo de los Muñecos" que actualmente funciona en la República de los Niños.

18. En una entrevista publicada en la revista La Maga en junio de 1992, VAIR también hace referencia a "un taller de filmación para niños en Vicente López": se refiere a El Mate, iniciativa de Irene Blei y Lucía Cano, fundado en 1987. El espacio fue refundado en 1999 como la "Primera Escuela de Cine Infantil y Juvenil". Blei trabajó junto a Iturralde en el ámbito universitario y tanto ella como Cano han reivindicado la figura y el aporte de VAIR a su proyecto.

19. Diario Clarín, domingo 13 de octubre de 1996.

20. http://intranet.malba.org.ar/web/prensa_det.php?id=20. Consultado 5/12/16.

Bibliografía <

Adduci Spina, E. (2015). "Sujetos u objetos: la construcción del imaginario infantil en la producción audiovisual para niños. Acerca de Víctor Iturralde Rúa y Goar Mestre", en revista Question, La Plata, vol. 1, № 46, abriljunio.

Cerezales, M. V. (2014). "Experiencias de lectura: posibles razones para incluir lo siniestro en el canon infantil”. Ponencia publicada en actas del Primer Simposio de Literatura Infantil y Juvenil en el Mercosur - Homenaje a María Delia Díaz Rönner.

Iturralde Rúa, V. A. (1960) AH Biografía de Alfred Hitchcock, Buenos Aires: Cineclub Núcleo. (1962). Yo pregunto a la jirafa, Buenos Aires: Norte. (1964). Qué ven, qué leen nuestros hijos, Buenos Aires: Editorial Universitaria de Buenos Aires. (1981). El ojo oye, el oído ve. Vida, obra y técnica de Norman McLaren: un genio del cine, Buenos Aires: Embajada de Canadá. 
(1984). Cine para los niños. Proposiciones para fundar cine clubes infantiles, Buenos Aires:

Corregidor. (1987). El bramido horripilante, Buenos Aires: Coquena - Libros del Quirquincho.

. (1987). El onésimo soñó un cuete, Buenos Aires: Coquena - Libros del Quirquincho.

. (1988). Los emplastos de Don Zafiro, Buenos Aires: Métodos.

. (1991). El invasor de los sueños, Buenos Aires: Métodos.

. (1991). Las cabezas sin hombres, Buenos Aires: Coquena - Libros del Quirquincho.

. (1993). (en coautoría) Re-divertido con letras $6^{\circ}$ y $7^{\circ}$ grado, Buenos Aires: La colmena.

(1994). Los dinosaurio de la seis de la tarde, Buenos Aires: Coquena - Libros del Quirquincho.

Manrupe, R. (2004). Breve historia del dibujo animado en la Argentina, Buenos Aires: Libro del Rojas.

Marín, P. (2014). “Investigadores de la forma. El cine de Víctor Iturralde y Luis Bras”, en revista Hambre, Vicente López, noviembre, pp. 14-18.

Romero, S. y Sancho, F. (2014). “Víctor Iturralde Rúa (1927-2004)”, en Malowicki, Alejandro (coord.) Historia del cine infantil en Argentina, Buenos Aires: APCI.

Scolamieri, G. (1946). Vida y espíritu de una escuela, Buenos Aires: La Razón.

Serra, M. S. (2011). Cine, escuela y discurso pedagógico. Articulaciones, inclusiones y objeciones en el siglo XX en Argentina, Buenos Aires: Teseo.

Hemerografía

B.I., “Cine como en la escuela” (entrevista), en diario Clarín, 5 de marzo de 1983.

Dátola, D., "Víctor Iturralde, un patriarca con alma de pibe”, en diario La Razón, 8 de abril de 1986.

Esteban, A., "La TV limita a los chicos" (entrevista), en diario Ámbito financiero, 20 de agosto de 1990, p. 12.

Fundación Universidad del Cine. Cartilla de seminarios 1992.

Garff, J., "Pequeños cineastas”, en diario Clarín, 19 de agosto de 1994.

Iturralde, V., “Y el respeto, ¿para cuándo?”, en revista Santiago, diciembre de 1984, p. 21.

Martínez, A., "Víctor Iturralde, un apasionado del cine" (necrológica), en diario La Nación, 4 de enero de 2004, p. 5. 
Mehl, R., “Víctor Iturralde tiene un duende en sus películas”, en diario La Nación, 9 de marzo de 1996, p. 3, cuarta sección.

S.E., "Algo que los niños perdieron”, en diario Clarín, 2 de febrero de 1980.

S/f, “'Biógrafo', evocación con silencio y piano”, en diario Clarín, 26 de abril de 1988.

S/f, “Iturralde Rúa: ‘El buen cine infantil aquí no se conoce’”, en diario Clarín, 15 de marzo de 1976.

S/f, "Sólo para bajitos", en diario Clarín, 3 de enero de 1992.

S/f, "Víctor Iturralde, “El cine debe ayudar al niño a pensar y a crecer”, en La Nación Revista, 2 de diciembre de 1984, p. 46. S/f, “Víctor Iturralde Rúa filmará 'Vientos de magia”, en revista La Maga, 10 de junio de 1992, p. 11.

S/f, “Víctor Iturralde: 'la respuesta está en ellos”, en diario Clarín, 9 de septiembre de 1976.

S/f, "Víctor Iturralde: 'se le falta el respeto al niño', en diario La Nación, 11 de octubre de 1981, p. 10, segunda sección.

Sendrós, D., "Víctor Iturralde acusa y pone en el banquillo a los programas infantiles de televisión", en diario Convicción, 3 de febrero de 1983, p. 23.

Silveyra, C., "La palabra innombrable”, en diario Clarín, 14 de enero de 1988.

Tello, N., "El niño debe participar, sentirse protagonista" - Planes de Víctor Iturralde, flamante asesor de ATC", en diario Tiempo Argentino, 25 de febrero de 1984, p. 15.

Tenewicki, I., “Víctor Iturralde Rúa, el papá de los cineclubes”, en diario Clarín, 13 de octubre de 1996.

Abstract: The career of Víctor Iturralde (1927-2004) is nowadays recognized in Argentina in fields as diverse as Film Studies, Cineclubism, Experimental Animation, Communication Research, Children's Literature or Cultural Management oriented to children. His work is a fundamental link in the development and transmission of artistic, cultural and intellectual traditions generally located on the margins of (or in opposition to) traditional institutions and mass media.

Key words: Víctor Aitor Iturralde Rúa - Children’s Cinema - Film Clubs - Animation - Film Critic.

Resumo: A trajetória de Víctor Iturralde (1927-2004) é hoje reconhecida em Argentina em campos tão diversos como os estudos de cinema, o "cineclubismo", a animação experimental, a pesquisa em comunicação, a literatura infantil ou a gestão cultural orientada as crianças. Seu trabalho constitui uma parte fundamental no desenvolvimento e a transmissão de tradições artísticas, culturais e intelectuais localizadas geralmente nas margens das instituições tradicionais e os meios massivos.

Palavras chave: Víctor Aitor Iturralde Rúa - cinema infantil - cineclubismo - animação - crítica cinematográfica. 
Víctor Iturralde Rúa y la especificidad de lo infantil. Un primerísimo primer acercamiento fue publicado de la página 213 a página228 en Cuadernos del Centro de Estudios de Diseño y Comunicación №74 